\title{
DIÁLOGOS INTERGERACIONAIS NA DOCÊNCIA NO ENSINO MÉDIO DE TERRITÓRIOS RURAIS: NARRATIVAS (AUTO)BIOGRÁFICAS DE PRÁTICAS EDUCATIVAS
}

\section{ADELSON DIAS DE OLIVEIRA}

Universidade Federal do Vale do São Francisco

\section{FABRÍCIO OLIVEIRA DA SILVA}

Universidade do Estado da Bahia

RESUMO O texto objetiva compreender como as experiências formativas de professores e jovens do Ensino Médio são construídas em contexto rural. A problemática explica-se pela questão norteadora: de que maneira os docentes significam suas práticas educativas e as inter -relacionam com a juventude e a contextualização do ensino? Como núcleos de sentido decorrentes do estudo, estão localizados: a identidade pessoal e profissional em contexto rural e a pertinência dos valores familiares, como significativos para a formação e o desenvolvimento da profissão, as condições de trabalho no âmbito das ruralidades e os sentidos do ensino médio nesse processo. É uma pesquisa qualitativa, fenomenológica, que toma como princípios a abordagem (auto)biográfica. Utiliza-se da entrevista narrativa como dispositivo de recolha de dados. Para a reflexão sobre os resultados, toma a análise compreensiva mediada pelos princípios da hermenêutica. Como resultados aparentes é possivel indicar a existência de divergências no entendimento do que significa a escola e o lugar de vivência, demarcado por distâncias geracionais, o que provoca, dessa forma, um afastamento nos propósitos do fazer educacional, pelo docente, e de viver a prática educativa, pelos jovens alunos, marcados pelo seu lugar.

Palavras-chave: Prática educativa. Docência. Ensino médio. Juventudes. Ruralidades. 


\section{ABSTRACT INTERGERATIONAL DIALOGUES IN TEACHING IN} MIDDLE EDUCATION OF RURAL TERRITORIES:

\section{NARRATIVE (AUTO) BIOGRAPHICS OF EDUCATIONAL PRACTICES}

The text comprehends how the formative experiences of teachers and young people of high school are built in the rural context. The problem is explained through the guiding question: In what ways do teachers mean their educational practices and interrelate them with youth in the contextualization of teaching? The study focus on the personal and professional identity of teachers within a rural context and the relevance of family values as significant for their education and the development of the profession and its working conditions in such the rurality. It is a qualitative, phenomenological research, based in the (auto) biographical approach. The narrative interview is used as a collection device. For reflection of the results, we take the comprehensive analysis mediated by the principles of hermeneutics. As a conclusion it is possible to indicate the existence of divergences in the understanding of what the school means for teachers and students according to their different experiences, demarcated by generational distances.

Keywords: Educational practice. Teaching. High school. Youths. Ruralities.

DIÁLOGOS INTERGERACIONALES EN LA DOCENCIA EN

\section{LA ENSEÑANZA MEDIO DE TERRITORIOS RURALES: NARRATIVAS (AUTO) BIOGRÁFICAS DE PRÁCTICAS EDUCATIVAS}

El texto busca entender cómo las experiencias formativas de profesores y jóvenes son construidas en la escuela secundaria en el contexto rural. El problema se explica por la pregunta orientadora: ¿Cómo los maestros significan sus prácticas educativas y como se interrelacionan con la juventud y la contextualización de la enseñanza? En el estudio se apuntan unidades de significado: una identidad personal y profesional en el contexto rural y relevancia de los valores familiares como importantes para su formación y desarrollo de la profesión y de sus condiciones de trabajo en las ruralidades y el sentido de la escuela secundaria este proceso. Se trata de una investigación cualitativa, fenomenológica. Toma como criterio principios del método autobiográfico. Se utiliza las 
entrevistas narrativas como dispositivos de recogida. Para la reflexión de los resultados, se utiliza el análisis exhaustivo mediado por los principios de la hermenéutica. Como resultados aparentes pueden indicar la existencia de diferencias en la comprensión de lo que la escuela y el lugar de experiencias, marcado por las distancias generacionales, lo que hace que el espaciamiento de este modo los efectos de hacer de la educación mediante la enseñanza y vivir la práctica educativa de los jóvenes estudiantes, marcados por su lugar.

Palabras clave: Práctica de la educación. La enseñanza. La escuela secundaria. Jóvenes. Ruralidades.

\section{Primeiros fios narrativos}

O desafio contemporâneo da docência está centrado na construção cotidiana de um diálogo produtivo e contínuo entre as diferentes gerações. De um lado, o professor com suas vivências, experiências e marcas constitutivas do saber e da prática, do labor diário ou até mesmo do início da carreira docente, jovem professor em que as buscas constantes por afirmação e autoconhecimento são frequentes. De outro, o jovem, aquele em que o instante vivido tem muito significado para ele, diante de um universo movido por mudanças instantâneas e que constituem suas marcas de experimentação e de existência. Diálogos necessários e relações de proximidade fazemse presentes em um movimento contínuo de construção da docência.

Construir uma relação em que esses universos possam significar um para o outro, sem causar a anulação, tende a ser o ponto nodal do desenvolvimento de práticas educativas, no âmbito da docência. Ao avançar para o campo do fazer educativo, nos territórios rurais, a dificuldade amplia-se, uma vez que incorpora ainda o desconhecimento dos contextos diversos em que alunos e professores estão imersos.

Motivados pelas inquietações apresentadas, este trabalho tem a intenção de provocar o leitor a voltar o olhar para as distâncias e aproximações que compõem a linha tênue entre a docência e as diferentes gerações que estão presentes no universo de uma escola localizada em território ${ }^{1}$ rural da região do Vale do São Francisco, mais especificamente na comunidade Angicos, distrito da cidade de Juazeiro - BA.

Este estudo apresenta, por intermédio da narrativa (auto)biográfica de uma professora, os encontros e desencontros geracionais, no contexto rural, presentes não só no espaço educativo em que ela está inserida, mas também em outros, em que suas práticas pedagógicas se evidenciam como elementos relacionais do seu fazer docente, oferecendo-nos, dessa maneira, elementos que nos possibilitam pensar a prática educativa no contexto rural.

1 Território aqui compreendido como possibilidade de definir o espaço geográfico, político e econômico, também entendido como a expressão dos relacionamentos entre tempo e política. Vincula a ideia de organização espacial, de acordo com as perspectivas culturais em que as comunidades possam controlar as habilidades necessárias para remodelar uma considerável extensão dos aspectos físicos e econômicos de um ambiente regional. Enfim, com a evolução do conceito de território é possivel constatar que este também versa pela possibilidade de constituir o bem comum para as pessoas que ocupam este espaço territorial. C.f. Jean Gottman, 2012. 
A narrativa emerge, como elemento de significação, favorecendo uma compreensão da docência e dos aspectos identitários que a compõem, toda a vinculação com o ambiente rural e ainda a construção do conhecimento mediado por aspectos intergeracionais, revelados, nesse contexto, que se singularizam na discussão, que aqui trazemos, pelas experiências narradas por uma professora. Ainda como objeto da escrita, pretende-se sinalizar para as reflexões que revelam as "ruralidades", compreendidas neste trabalho, para além de lugar em que os sujeitos tecem suas redes de experiência. Logo, o contexto rural que analisamos, neste estudo, tem relação com as novas configurações produzidas no âmbito social, a partir dos aspectos da globalização e de políticas neoliberais que produziram um fluxo distinto entre o urbano e o rural, principalmente no que diz respeito aos movimentos de luta e resistência que foram surgindo no seio dos movimentos sociais em que o cenário contemporâneo contempla outras possibilidades de viver e significar o espaço, o território, o lugar de vida e de experiência dos sujeitos (CARNEIRO, 2002; 2005; MOTA; SCHMITZ, 2002; VEIGA, 2002; WANDERLEY, 2000; SOUZA et al, 2011); e como estas estão presentes no cotidiano dos sujeitos docentes e jovens nelas inseridos.

Para construir as reflexões aqui elucidadas, tomou-se como elemento norteador a (auto) biografia, compreendendo-a como dimensão de pesquisa e como prática de formação que se remete a narrativas e experiências dos interlocutores como elementos possibilitadores de construções de identidade, individuais e coletivas, mediados pela entrevista narrativa como dispositivo de recolha (SOUZA, 2014). Para a análise da entrevista, adota-se o princípio compreensivo, com base em Bertaux (2010) e Souza (2014).

Assim, o texto está estruturado da seguinte maneira: reflexão e descrição metodológi- ca sobre o trabalho construído. Construções teóricas e analíticas tecidas pelos núcleos de sentidos revelados na narrativa e, por fim, uma sessão que retoma os principais elementos, entre desafios, perspectivas e possibilidades em que a narrativa da docente aponta como significativa para pensar o ambiente de sala de aula e toda a sua construção no contexto em que está inserida.

\section{No rumo do roçado: descrição e reflexão metodológica}

As experiências de reconhecimento produzem outras posturas individuais nas relações sociais entre as pessoas e o ambiente em que estão inscritas. (PIMENTEL, 2013, p. 250)

Saber reconhecer-se diante de si e do outro é uma tarefa que exige um profundo mergulhar em si, na busca de encontrar-se diante de um emaranhado de relações, pessoas, afazeres. Você está lá, em algum lugar, e o encontro consigo mesmo exige romper as amarras e vendas que nos fazem sair do lugar e enxergar além do óbvio. A provocação para experienciar o encontro é a principal condição para descobrir o caminho e estabelecer novas relações, novas experiências e, enfim, reconhecer-se.

A abordagem (auto)biográfica está diretamente relacionada, diria que fundamentada, nas bases de uma fenomenologia existencial, que visa produzir compreensão sobre a fala dos sujeitos, autores de suas histórias e de suas próprias experiências. Assim, a utilização desta abordagem, nas pesquisas em educação, e não será diferente no caso da pesquisa em tela, visa, entre outros objetivos, compreender como as experiências formativas de professores e jovens do Ensino Médio são construídas em contextos rurais.

A partir de um esquema de conceitos que se produzem desde as narrativas e relatos de experiências educativas pelos quais cada um 
passa, ao longo do seu processo formativo, busca-se reconstruir a trajetória formativa dos sujeitos investigados.

Esta abordagem difere de outros modelos, por não isolar as trajetórias biográficas singulares dos eventos sociais, em sua complexidade. 0 evento social, e nesse caso o educativo, assume uma posição relevante, no cenário das pesquisas (auto)biográficas, uma vez que permite aos indivíduos compreenderem os sentidos das ações que desenvolvem, ao longo da vida, principalmente em se tratando de processos formativos e de atuação profissional na docência.

Nesta pesquisa, a justificativa para a escolha deste método não seria outra, se não a de perceber que a abordagem (auto)biográfica permite ao sujeito revisitar sua trajetória, buscando ver nela como o ser professor se constitui no movimento de sua vida, cristalizada em experiências que moldam a forma de pensar e de agir de uma pessoa. Ademais, tal abordagem permite ao pesquisador interagir diretamente com o sujeito de sua pesquisa, recorrendo aos processos interlocutórios, como forma de possibilitar ao sujeito dar sentido a sua própria trajetória, por meio da linguagem que emana das narrativas diversas produzidas por alguém que fala de si, a partir da condição de um ser humano, que vive, atua e age sobre um mundo, produzido no cotidiano e na relação com o outro.

Para caminhar, é preciso ter uma direção; na pesquisa, não é diferente. A necessidade de reconhecimento diante daquilo que ainda não se sabe é uma constante e precisa ser, a cada momento, descontruída, erguida e novamente desfeita. Nessa perspectiva, o estudo em tela traz em seu caminhar a doçura e o amargor que o semiárido apresenta, de maneira particular, o contexto rural.

O estudo foi realizado na escola da comunidade de Angicos, distrito da cidade de Jua- zeiro, no Norte da Bahia, localizada a $47 \mathrm{~km}$ da sede. É uma área de sequeiro, onde a população concentra sua renda na produção pecuária de caprinos e ovinos. É considerada como uma fazenda, ou aglomerado de pequenas propriedades agropecuárias familiares, que, juntas, compõem a comunidade em que a escola, cenário do estudo, está localizada. De forma complementar, é pertinente sinalizar que o referido lócus está vinculado ao distrito de Pinhões, cidade de Juazeiro, Bahia, Brasil.

O estudo foi realizado diretamente na Escola Antonila de França Cardoso, que atende ao público, da Educação Infantil ao Ensino Fundamental II, e, no período noturno, o espaço é utilizado pela Escola Estadual Pedro Raimundo Moreira Rego, localizada no bairro urbano de Piranga, periferia da cidade, que oferece o Ensino Médio presencial na comunidade, todavia, todas as responsabilidades e atribuições quanto a modalidade são da escola que está localizada na área urbana da cidade de Juazeiro/BA. O formato é conhecido como anexos e é aplicado em várias comunidades das cidades situadas no Estado da Bahia.

Na cidade de Juazeiro, a experiência conta com 21 (vinte e um) anexos de Ensino Médio, funcionando em escolas do campo, dentre esses o anexo da escola em que a entrevista foi realizada. Na comunidade de Angicos, a escola atendeu, no ano de 2015, a um total de 98 alunos.

Nesse sentido, para o desenvolvimento do trabalho, foi utilizado como princípio a abordagem (auto)biográfica, uma vez que "a narrativa (auto)biográfica instala uma hermenêutica da história de vida, isto é, um sistema de interpretação e de construção que situa, une e faz significar os acontecimentos da vida" (DELORYMOMBERGER, 2008, p. 56). Utilizou-se, também, das memórias de formação e da prática docente, trazendo à tona os aspectos inerentes à constituição desse processo intrarreflexivo, na 
relação que o docente faz, pela análise de sua prática, nos momentos de formação. Assim, este processo reverbera na ação educativa dos sujeitos, aqui, no caso, os jovens estudantes do campo e/ou territórios rurais, em uma perspectiva intergeracional. Afirma-se então que:

falar de si torna-se uma tarefa não muito fácil, pois envolve um processo de rememorizar e reviver momentos que fizeram parte da vida do sujeito. A fala do sujeito que narra pode vir repleta de aspectos voltados para a emoção e hesitações, por sua vez, o estudioso de história de vida encontra desafio em extrair da enunciação informações disponibilizadas e aspectos que desvelem e estão presentes no cotidiano da sociedade que permitam a sua compreensão. (OLIVEIRA, 2014, p. 22)

A narrativa toma, neste estudo, o lugar do enunciado das experiências de formação de docentes que atuam no processo de ensino de sujeitos jovens que vivem no campo contemporâneo, no sentido de enunciação dos percursos sob os quais esses processos estão constituídos. A narrativa de vida e formação, assim apresentada, pode ser compreendida como a totalidade dos fatos e experiências que o sujeito vivencia; todavia, para este estudo, toma-se a perspectiva de que a narrativa de vida apresentada caminha na direção de que o sujeito narra um fato vivido, uma experiência a outra pessoa, nesse caso, o pesquisador, e significa dizer que a produção discursiva do sujeito tomou forma narrativa (BERTAUX, 2010). Além disso, para este estudo, amplia-se o entendimento de que é o processo narrativo que contribui para a produção do sujeito diante da sociedade.

0 trabalho com narrativas é crescente, nas pesquisas em áreas sociais e humanas, considerando-se que estas estão presentes nas mais variadas experiências e espaços da sociedade. Utilizar as narrativas, como perspectiva teórica e metodológica, nas pesquisas em educação, particularmente para se pensar a docência e seus processos, aproxima o pesquisador das singularidades que compõem as vivências e experiências dos sujeitos em formação.

A entrevista narrativa configura-se na abordagem (auto)biográfica como um dispositivo que nos permite depreender os saberes que um sujeito construiu ao longo de uma trajetória de formação ou até mesmo de vida. Esses saberes poderão servir como forma de orientação para que se possa descrever e analisar as experiências educativas que o sujeito desenvolveu, ao longo de sua atuação em práticas educativas. A escolha deste dispositivo justifica-se, dentre outros motivos, pelo fato de que:

[...] através da narrativa, as pessoas lembram o que aconteceu, colocam a experiência em uma sequência, encontram possíveis explicações para isso, e jogam com a cadeia de acontecimentos que constroem a vida individual e social. (JOVCHELOVITCH; BAUER, 2007, p. 91)

Ademais do fato de que a entrevista narrativa favorece ao sujeito a ordenação e a sucessão de suas experiências, buscando explicar os acontecimentos que demarcam suas experiências profissionais na vida social, justificamos ainda a escolha deste dispositivo pelo fato de que ele permite perceber como os professores abordam os sentidos das práticas educativas pelas quais passam, ao longo de sua docência no Ensino Médio, em contextos rurais. Desta feita, destacamos a sua pertinência pelo fato de que, na entrevista narrativa, a:

[...] coleta de dados empíricos se ajusta à formação das trajetórias; ela permite identificar por meio de que mecanismos e processos os sujeitos chegaram a uma dada situação, como se esforçam para administrar essa situação e até mesmo superá-la. (BERTAUX, 2010, p. 27)

Vimos como pertinente, portanto, o fato de que este dispositivo possibilita a combinação de diferentes histórias formativas, que são relacionadas às próprias práticas educativas, 
procedimento que possibilita perceber como os sentidos da própria atuação vão se constituindo como meios de estabelecer diálogos intergeracionais, em que professor e estudantes, em contextos rurais, no Ensino Médio, produzem sentidos para aquilo que fazem no espaço educativo.

Diante disso, percebemos que as entrevistas narrativas não se constituíram apenas em uma listagem de acontecimentos das práticas educativas de um sujeito, como forma de ordenação aleatória de sua trajetória de vida e profissão. Para além disso, este dispositivo se constituiu em uma arte de relacionar os acontecimentos da prática educativa, em um novo tempo e sentido que se atribui, caracterizando novas experiências.

Com a narrativa foi possivel ao professor que narra alinhar os acontecimentos de modo a criar um enredo, estruturado por uma concepção de espaço e tempo formativos, que dão sentido à trajetória do sujeito, permitindo, assim, o desenvolvimento de uma história que tem começo e fim e que pode sempre ser reconstruída, em um novo tempo e espaço, logo produzindo novos sentidos. Trata-se, portanto, de um dispositivo que favorece uma organização dos fatos relevantes da vida de uma pessoa, que, ao narrá-los, os organiza de forma a potencializar as experiências vividas, apoiando-se na oralidade e na competência reflexiva que a linguagem the permite fazer. Souza (2008, p. 91) nos diz que:

As entrevistas narrativas demarcam um espaço onde o sujeito, ao selecionar aspectos da sua existência e tratá-los através da perspectiva oral, organiza suas ideias e potencializa a reconstrução de sua vivência pessoal e profissional de forma auto reflexiva como suporte para a compreensão de sua itinerância vivida [...].

Considerando que um dos objetivos deste trabalho é o de compreender como os docentes significam suas práticas educativas e as in- ter-relacionam com a juventude e o contexto de ensino, este dispositivo é um instrumento relevante para analisar a forma e o sentido construídos a partir das experiências formativas de professores e jovens do Ensino Médio, em contextos rurais. A entrevista narrativa permite construir uma articulação da experiência formativa, produzindo um diálogo entre o individual e o sociocultural, em que o sujeito vai mobilizando saberes do arsenal de conhecimentos adquiridos durante a prática educativa. 0 trabalho com as narrativas pode ser realizado de maneira individual e grupal. Na escrita deste texto, optou-se por utilizar apenas uma narrativa de docência. A entrevista narrativa foi realizada no local de atuação da docente, na escola Antonila de França Cardoso, comunidade de Angicos, em novembro de 2015.

Para analisar a narrativa, optamos pela análise compreensiva, que se fundamenta nas discussões apresentadas por Bertaux (2010), uma vez que se tem o objetivo de explicitar as informações e significações nela contidas. Nessa mesma perspectiva, as reflexões de Josso (2010) sobre o método da análise compreensiva da experiência de vida são também evidenciadas nesse processo. Essa forma de análise tem sua construção por meio do método hermenêutico, tendo, ainda, como referência principal, as reflexões apresentadas por Gadamer (1997) e Delory-Momberger (2008), autores que aproximam a metodologia dos aspectos da hermenêutica, dando ênfase à interpretação dos fatos vivenciados. Uma vez que:

A narrativa autobiográfica instala uma hermenêutica da 'história de vida', isto é, um sistema de interpretação e de construção que situa, une e faz significar os acontecimentos da vida como elementos organizados no interior de um todo. [...] A compreensão desenvolvida a partir da inteligibilidade de sua própria vida revela ao pesquisador a capacidade epistemológica de aderir a sentidos que não eram os seus e reconstruir relações significantes particulares ao 
seu objeto de estudo: época da história, sistema cultural, instituição, obra de arte ou personalidade histórica. 0 princípio mesmo de uma ciência humana constrói-se com base na autorreflexão e na auto-interpretação que o homem, aqui o historiador ou pesquisador, é capaz de realizar sobre si mesmo a partir de sua própria experiência de vida. (DELORY-MOMBERGER, 2008, p. 56-57)

A análise compreensiva em que se pauta o estudo, para ir além das significações apresentadas pelos narradores, é uma perspectiva que tem como essência a funcionalidade do verbo "compreender" que exprime, dessa maneira, o espírito da análise.

Os processos de análise de narrativas na abordagem (auto)biográfica constituem-se em uma situação comunicativa que leva em consideração sobretudo os sentidos manifestados pelos sujeitos que narram. No entanto, o processo de análise de entrevistas considera alguns critérios, para garantir que o material esteja condizente com a proposta metodológica. Assim, o processo de transcrição deve ser o mais fiel possivel do que narrou o entrevistado.

Os fatos narrados são sempre significativos por causa da riqueza de significados que se atribuem às experiências de cada um. 0 que importa na análise compreensiva-interpretativa não é a causa, mas as significações que as narrativas encerram. Por isso, importa perceber, no âmbito da abordagem (auto)biográfica, seus objetivos e seu valor para o sujeito que a produz. Por este raciocínio, o sentido que se atribui às experiências é o sentido que delas emergem pelos movimentos e momentos vividos pelo sujeito. Nesta seara, as experiências são vividas, sentidas, e, por assim serem, são passiveis de atribuição de significados. Assim, as experiências educativas são relevantes para aqueles que estão em um processo formativo. O ser humano procura compreender e explicar o mundo a sua volta. Para Ricoeur (1996), a compreensão é resultado de uma explicação que se dá para as coisas humanas e também não humanas. Isso sugere que a explicação, antes da própria compreensão, é a tradução da realidade em um significado que tenha sentido e se processe por uma determinada linguagem, ou signos linguísticos que nos permitam e possibilitem uma comunicação compreensiva do real.

O sentido e sua interpretação, segundo Ricoeur (1996), nos dirigem à compreensão e à explicação. Estes não podem ser concebidos como processos separados, mas como dois polos que se complementam dialeticamente. Compreender significa explicar o sentido das significações atribuídas à realidade das coisas e do mundo. Seja qual for a abordagem utilizada, é próprio do ser humano significar e, através da interpretação, compreender toda a complexa realidade que o envolve. Para compreender o sentido das trajetórias formativas de uma pessoa, é preciso passar pela explicação de como essa trajetória se consolidou. Essa explicação tem origem nas narrativas. Assim, é possivel inferir que a compreensão é um resultado, inacabado, de um processo de explicação.

\section{Perfil biográfico Flor de Mandacaru ${ }^{2}$}

Flor de Mandacaru é professora de Língua Portuguesa, com especialização em Psicopedagogia. No Ensino Médio, cursou magistério onde teve o primeiro contato com a docência. Apresenta-se como uma professora apaixonada pelo fazer docente e que atua em sala de aula há 26 (vinte e seis) anos. Sua primeira experiência enquanto docente deu-se ainda enquanto cursava o terceiro ano do magistério, no ano de 1989, em uma turma de alunos especiais. Narra que iniciou os estudos com quase

2 Pseudônimo utilizado para preservar a identidade da interlocutora/narradora, conforme critérios de submissão e aprovação do comitê de ética. 
12 (doze) anos de idade, uma vez que morava em uma área rural e, na época, era muito dificil estudar, principalmente para mulheres. Somente, ao ir morar na cidade, já com a idade acima descrita, teve a oportunidade de começar a estudar. Revela que seu sonho sempre foi ser professora, mas enfrentou muitas dificuldades para conseguir atuar em sala de aula.

Em sua narrativa, Flor de Mandacaru deixa clara sua relação íntima com o espaço rural. Nasceu e viveu até quase 10 (dez) anos em uma comunidade rural e saiu para morar na cidade, em decorrência das dificuldades para encontrar trabalho e por causa da falta de investimento em políticas para amenizar os efeitos da seca. "Fomos pra cidade para não morrer de fome" - algo que relata ao longo de sua narrativa e, acrescenta, de forma muito enfática, que foi arrancada do meio rural, mas que não queria sair de lá. Demarca que sua experiência, após formada, foi em turmas de Educação de Jovens e Adultos do Programa MOVA (Movimento de Alfabetização) Brasil, e também como professora de reforço escolar. No campo de sua atuação, faltava-lhe ainda a contribuição em turmas de Ensino Médio e a experiência no contexto rural.

É uma professora de emoção aparente e que se sobressai muito mais quando traz em sua narrativa o momento em que passa a assumir a sala de aula, no ambiente tão familiar a suas memórias de criança e que se misturavam às vividas por seus pais. Ali naquele lugar, ela se reencontra com suas emoções, que estavam guardadas, elementos fortes que escapam na forma de falar, ao narrar os fatos que foram se constituindo e construindo nela o ser professora. Em sua relação com os contextos rurais, identifica-se como "caatingueira", e esse é o primeiro choque de gerações que ela enfrenta, ao perceber que os seus jovens alunos não conseguem enxergar tantos potenciais e tantas alegrias naquele lugar.
É uma estudante curiosa e permanente que precisou abdicar de muita coisa, por ser mãe solteira:

eu sou PÃE, que é uma dificuldade maior pra você, às vezes você tem que abdicar de várias coisas pra poder ter uma, dar uma condição maior né, ao seu filho e entre assim, pai e mãe que é de verdade, ele prefere tirar o pão da sua boca pra dar ao filho, e nunca deixar faltar pra ele, então, por causa de alguns percalços nesse sentido, eu fiquei estudando apenas em trabalho na escola e aí nunca parei, eu sou curiosa, ficar estudando, qualquer coisa, em todo lugar, o que é possivel e aquilo que não é a gente faz ser possivel. (FLOR DE MANDACARU, ENTREVISTA NARRATIVA, 2015)

A trajetória narrada pela professora é cheia de emoções e marcada por encontros e desencontros com a ação docente e o diálogo entre as diferentes gerações em que a escola vai se constituindo e provocando rupturas.

\section{A docência na roça e as práticas educativas intergeracionais no ensino médio}

[...] mas faltava algo, sempre falta, faltava essa parte do vir para uma área rural. (FLOR DE MANDACARU, ENTREVISTA NARRATIVA, 2015)

A narrativa da professora Flor de Mandacaru é simbolizada por uma série de momentos afetivos com o lugar - aqui significado pelo contexto rural, não como palavra sinônima, mas como constituição identitária e de referência de vida - e a significância deste em sua vida. Ao se apresentar, evidencia logo os sentidos do ser professora em sua vida e o quanto tem sentido para si todas as relações constituídas ao longo desse processo prático e formativo. É muito forte, em sua fala, a busca constante por formação e esse caminhar se faz em sua vida, muito fortemente, pela autoformação. A docência na roça para ela sempre foi algo que Ihe faltara, enquanto pessoa e profissional. Tal 
aspecto demonstra, para nós, a importância da implicação com o espaço de atuação para, dessa maneira, provocar a construção de rupturas com aquilo que é dado como pronto no universo da docência.

Diante do exposto, ao analisar a narrativa da professora, é possivel enveredar a discussão para alguns núcleos de sentido que vão se configurando, como a identidade pessoal e profissional, no contexto rural, e a pertinência dos valores familiares como significativos para sua formação e o desenvolvimento da profissão, as condições de trabalho, no âmbito rural, e nesse caso mais específico pela presença e atuação no Ensino Médio. Vale ressaltar que as reflexões sobre os núcleos acima apresentados serão discutidas ao longo da escrita deste trabalho.

Consideramos pertinente o debate sobre os sentidos que o Ensino Médio toma, em sua vinculação à formação dos jovens do nosso país, uma vez consideradas as justificativas para a elaboração de novas diretrizes curriculares do Ensino Médio, anunciadas no parecer CNE/CEB n. 5/2011, que dizem respeito a mudanças recentes na legislação e na política educacional, tais como a criação do Fundo de Manutenção e Desenvolvimento da Educação Básica e de Valorização dos Profissionais da Educação (FUNDEB), e a ampliação da obrigatoriedade da escolarização. De acordo com as novas diretrizes curriculares para o Ensino Médio:

0 desencaixe entre a escola e os jovens não deve ser visto como decorrente, nem de uma suposta incompetência da instituição, nem de um suposto desinteresse dos estudantes. As análises se tornam produtivas à medida que enfoquem a relação entre os sujeitos e a escola no âmbito de um quadro mais amplo, considerando as transformações sociais em curso. Essas transformações estão produzindo sujeitos com estilos de vida, valores e práticas sociais que os tornam muito distintos das gerações anteriores. Entender tal processo de transformação é relevante para a compreensão das di- ficuldades hoje constatadas nas relações entre os jovens e a escola. (BRASIL, 2011, p. 13)

Tais questões apontam para se pensar uma escola que dialogue com as perspectivas e anseios que os jovens sinalizam em seu projeto de vida. O Ensino Médio aqui compreendido não apenas como o momento de finalização da fase de escolarização, mas como o espaço de mediação entre o que o jovem vive e aquilo que será tomado como futuro em vida. Considerar os estilos de vida, os valores e práticas sociais presentes nas distintas gerações que fazem parte do cotidiano do Ensino Médio, como apontam as DCEM, é um elemento fundante para se estabelecer laços com a pretensão de oferecer educação significativa e sua efetivação.

É lógico que o debate até então circunda uma perspectiva de se direcionar a formação do jovem para o mundo do trabalho apenas, não considerando aí aspectos de uma subjetividade que também precisa ser considerada, para efetivamente constituir elementos que possibilitem a esses sujeitos por si só definirem os rumos que suas vidas irão tomar.

Articular a necessidade de redimensionar o Ensino Médio no Brasil, para atender as demandas contemporâneas tem relação direta com a necessidade de considerar os aspectos contextuais em que a globalização tem forte influência, especialmente, no tocante às ruralidades. Olhar as ruralidades como uma ação contra-hegemônica requer também o pensamento de uma existência, a partir das relações com algo que significa a cultura, como não rural, outros contextos sociais que estão presentes no espaço e no tempo de desenvolvimento das ruralidades (MOREIRA, 2005). Nesse interim, cabe extrapolar os estereótipos presentes no imaginário social e constituídos ao longo da história. O esforço para articular tais discussões está presente na narrativa em evidência no estudo em questão: 
Uma das coisas que eu fiquei assim, além de ficar feliz de estar tendo a oportunidade de ensinar fundamental Il e ensino médio, era aquela alegria e a satisfação de ser na zona rural, numa área rural, de ter aquele público que eu observava e aí eu vou dizer que no primeiro eu fiquei assim, teve uma pontinha de frustração porque eu vim com aquela alegria, aquela satisfação, achando, eu acho que eu me coloquei, se fosse eu enquanto sou da área rural, enquanto aluna da área rural, eu acho que eu viria assim com uma experiência muito grande da minha vivência enquanto moradora da área rural e isso vai me ajudar né, eu associar a parte de escola que é pra ter um desenvolvimento maior, eu chego começo a conversar com os alunos, tem sempre aquela história de você conhecer a turma, saber quem são, de onde vem, um pouquinho da história deles e quando eles chegam pra conversar com a gente, muitos deles, acham que por morar na cidade não sabe nada da área rural, ou o que sabe é muito superficial e aí uma das frases interessantes, eu tinha acabado de ler algo em uma revista onde a pessoa que escreveu, não me lembro agora faz ano, 2010, não me lembro quem escreveu, falava justamente da questão do preconceito rural, em que chegou numa determinada localidade e ao se expressar, é, com o grupo falando sobre caatingueiro, que ele não usou assim questão de ser assim um preconceito, mas caatingueiro, por pertencer a um local onde o bioma é a caatinga, e as pessoas o receberam muito mal e não entenderam, interpretaram de forma inadequada, justamente achando que ele estava com preconceito chamando de caatingueiro. (FLOR DE MANDACARU, ENTREVISTA NARRATIVA, 2015)

A narrativa faz emergir novas compreensões, no tocante ao contexto em que está localizada a sua atividade laboral. Aponta para a ressignificação do rural, como espaço singular, porém com atos coletivos e de construção histórica em um espaço diversificado, o que o torna um desafio constante para o desenvolvimento da prática da docência, junto aos sujeitos que ali vivem.

Lida-se, cotidianamente, com a interpretação do lugar do atraso e ligado apenas à na- tureza, aspecto este que dialoga diretamente com o que sinaliza Moreira (2005), quando problematiza as "ruralidades", como novas identidades que estão em construção, e avança para a reflexão de que este seja o espaço de constituição de relações específicas dos habitantes do campo e a natureza, elemento fundante para se conceber o rural não como uma dicotomia entre cidade e campo, mas como um espaço de significação de saberes e identidades construídas e ao mesmo tempo influenciadas por ações oriundas da globalização.

No cenário contemporâneo, não se percebe o rural, único e hegemônico, pois nele incidem concepções distintas deste espaço e daí outros rurais, ou significações são atribuídos. Surge, nessa lógica, em um mesmo contexto, ruralidades distintas, vividas e experiênciadas pelos sujeitos ali presentes.

Sendo assim, ao narrar que o trabalho no rural é a realização de um desejo forte, Flor de Mandacaru verbaliza também os sentidos subjetivos de como percebemos o nosso contexto, às vezes sob a influência das informações massificadas que constroem uma visão homogênea de lugar, o que dificulta a ampliação do olhar para a proporção do que, de fato, o lugar é, ou seja, os sentidos e significações que podem ser inferidos pelos sujeitos de seu contexto, nesse caso, do rural. Outro aspecto que merece atenção é o fato de apontar para o sentido do conhecimento superficial e a reprodução desse conhecimento, sendo uma preocupação grande, em especial, quando se trata de trabalhar com o público jovem do Ensino Médio.

Arroyo (2014, p. 54), provoca-nos a construir uma nova possibilidade de Ensino Médio, nos fazendo refletir sobre:

quando as escolas, os coletivos docentes e até as Diretrizes Curriculares do CNE se propõem repensar os currículos do Ensino Médio - perguntar-nos que práticas inovadoras estão 
acontecendo nas escolas, nas diversas áreas do conhecimento. Se o conhecimento é um campo dinâmico, o currículo não pode ser reverenciado como um campo estático, mas como um território de disputa no que diz respeito à forma como o próprio conhecimento é disputado na sociedade. Trata-se de reconhecer o currículo, na prática, como um território de saberes e incertezas.

Os aspectos do pensamento curricular em que o Ensino Médio se pauta devem proporcionar a produção de um conhecimento que seja significativo, mas fazer isso, na lógica do currículo vivido no nosso país, é de fato evidenciar os territórios de disputas, que tomam a forma de aspectos que não são claros e denotam a marca colonizadora e hegemônica existente nas práticas educacionais do nosso país, de forma particular no contexto rural. Diante do exposto, a extensão ou o alcance do saber são tidos como primordiais para o processo de aprendizagem e de significação.

É no Ensino Médio que ocorre de fato o encontro entre as gerações, no processo de ensino e aprendizagem. De um lado, os docentes com toda a sua carga de experiência e conceitos preestabelecidos sobre a vida e a as tendências sociopolíticas engendradas em seu fazer. De outro, os jovens, cheios de desejo e intento por conhecer o mundo que lhes propõe ousar e mergulhar nas descobertas. Estabelecer um elemento de comunhão entre as duas dimensões vividas por estes sujeitos torna-se, então, o principal desafio na construção do saber e traz as incertezas apresentadas por Arroyo (2014), reforçando a necessidade de olhar o espaço de disputa por poder por ele proposto.

Cabe, então, um destaque para a relação que se estabelece entre o professor e o aluno, nesse caso, o jovem, no âmbito do Ensino Médio e o desenvolvimento de suas práticas educativas. Concebemos práticas educativas, aqui, como o aspecto que vai além do espaço da sala de aula, que provoca a vinculação com os diversos ambientes em que os sujeitos envolvidos no processo produzem saber e a partir daí os ressignificam, mediante suas experiências. Diante disso, é possivel elucidar que existem aspectos limitantes, no que diz respeito às inovações docentes, no desenvolvimento didático, elemento que dificulta a aproximação com os estudantes. Algumas reflexões são apontadas para:

[...] um dado que limita a criatividade docente: as condições precárias de viver de tantos adolescentes - jovens, até adultos - que chegam aos cursos de educação média. Porém, esse precário viver-sobreviver dos educandos tem instigado coletivos docentes a serem mais criativos, renovarem currículos, conhecimentos, didáticas, processos, material didático. Há um avançar tenso de reinvenção da docência e dos currículos como resposta ao precário e injusto viver dos novos educandos e educandas que acedem à educação média. Que experiências sociais vivem, que indagações e que leituras levam às escolas sobre seu viver, sobre a sociedade, a cidade, o campo? (ARROYO, 2014, p. 58)

Neste sentido, as práticas educacionais precisam condizer com as particularidades dos sujeitos que dão sentido à existência nesse ambiente. A escola toma um lugar de destaque na vida desses sujeitos e acaba assumindo papel importante no processo de construção identitária e formativa e, se esta escola não for significativa na vida dos jovens, fatalmente se tornará apenas um ambiente obrigatório que eles devem frequentar. É um paradoxo existente e que não pode ser desconsiderado, no processo reflexivo, ao se pensar em como a escola, na contemporaneidade, chega aos milhares de estudantes e cumpre a sua missão maior, que é levar conhecimento, socializar e, acima de tudo, a condição de discernimento das escolhas que balizarão os projetos de vida na sociedade contemporânea. Desta forma, é válido ressaltar que é preciso "contextualizar o 
seu objeto para ser pertinente" (MORIN, 1999, p. 39). Como um dos marcadores da experiência de formação desses sujeitos, a escola tem grande destaque, especialmente a prática pedagógica docente e toda a sua relação com o cotidiano vivenciado pelos jovens que estão imbricados ao campo. Nesse sentido, compreendemos que:

[...] muitas experiências têm praticado a educação contextualizada de modo exemplar, sem cair no bairrismo ou no basismo, que pretenda algum tipo de 'preservação do contexto'. Muitas experiências que conheço têm sim o contexto como ponto de ancoragem dos processos pedagógicos, mas para fincar aí e a partir daí as condições da mudança com os outros das 'narrativas hegemônicas', cujas colorações são de caráter étnico, etário, de gênero, territorial, ambiental, ético, estético, etc. (MARTINS, 2009, p. 30-31)

Corroborando com o que o autor apresenta, acredita-se que o processo de escolarização dos jovens do campo precisa considerar as vivências de cada sujeito, no sentido de construção de novos discursos e práticas sociais. Nesse percurso, não pode ser desconsiderado que a constituição familiar desses sujeitos seja oriunda de matrizes culturais camponesas e que traga consigo saberes tradicionais seculares, na maioria dos casos desconhecidos ou ignoradas pelo sistema educacional, aplicando a eles um processo formativo homogeneizado e urbanocêntrico (RAMOS, 2013). Um movimento de formação construído entre a cidade e o campo, no qual o jovem é deslocado de seu local de origem e passa a conviver com experiências curriculares distantes de seu contexto, fazendo, nesse movimento, um distanciamento de sua realidade. A formação docente precisa, nesse sentido, considerar que cada indivíduo é singular e, na junção das singularidades, é que o plural acontece. Não se constrói aprendizagem significativa isolando os contextos e as experiências vividas pelos sujeitos, por isso:
Somente um ser é capaz de sair de seu contexto, de distanciar-se dele para ficar com ele; capaz de admirá-lo para, objetivando, transformá -lo e, transformando-o, saber-se transformado pela sua própria criação; um ser que é e está sendo no tempo que é o seu, um ser histórico, somente este é capaz, por tudo isto, de comprometer-se. (FREIRE, 1981, p. 17)

Nesse caminhar, a professora desvela, em sua narrativa, que é pertinente um novo olhar para o ambiente rural, que não está mais atrelado à visão do atraso e da negligência. Aceitar o desafio proposto por Freire é também iniciar um novo ciclo de compreensão desse ambiente.

[...] se hoje dissesse assim, com o conhecimento que você tem eas condições que estão né, no interior agora que graças a Deus com todos os investimentos que toda forma tem aí, vem projetos onde a pessoa trabalha ali e vive ali mesmo, eu digo a você, se eu tivesse a escolha, eu voltaria para a área rural, mas como eu estou aqui e estão me dando a oportunidade, enquanto aqui eu puder continuar, daqui eu não saio, daqui ninguém me tira. (FLOR DE MANDACARU, ENTREVISTA NARRATIVA, 2015)

O comprometimento com o seu lugar ou o reconhecimento de suas potencialidades somente serão válidos, se fizerem parte do seu cotidiano. A formação docente não pode ficar deslocada, então, dessa premissa, ao mesmo tempo que não pode se fechar na formação inicial. Somente com o processo contínuo de reflexão sobre a prática possibilitará ao sujeito docente ressignificar o seu fazer. Tal premissa tem garantia na legislação brasileira e não se pode furtar esse direito a esse público, sendo necessário "levar em consideração os elementos das intersubjetividades no processo de formação, considerando o que o sujeito constrói enquanto sujeito singular" (REIS; SANTOS JÚNIOR, 2013, p. 142).

Corroborando com o exposto, acreditamos que a formação docente necessita garantir aos professores a condição de dialogar com 
os mais diversos aspectos da sociedade e com direitos igualitários, possibilitando, assim, que o sujeito não fique restrito à aplicação de receitas prontas e ao desenvolvimento de ações que não gerem significados para a vida dos alunos.

Nesse ínterim, tratar de formação docente para o campo remente a processos históricos de desvalorização e desmotivação para essas pessoas, particularmente no que concerne aos baixos salários e ao pouco valor dado à profissão docente para atuar no campo. 0 investimento na qualidade do ensino e na disponibilização para a população do campo, nas diversas modalidades de ensino da Educação Básica, remonta há pouco mais de 20 anos (entre o final do século XX e início do século $X X I)$. Assim, é pertinente pontuar que a formação para atuar nesse espaço rural, tomando com princípio as bases ideológicas e políticas da educação do campo, não deve ocorrer de forma alheia ao seu contexto, sendo relevante considerar que:

[...] além dos conhecimentos sistematizados, outros saberes complementam o processo de profissionalização, provenientes da comunidade [...] o sentimento de pertencimento ao grupo e os saberes proporcionados pela formação inicial e continuada produzem um outro olhar sobre a realidade dos sujeitos do campo. (RIOS; VICENTINI, 2013, p. 125)

O que as autoras apresentam corrobora diretamente com a perspectiva de se pensar a formação docente incluindo-se o viés da contextualização do ensino, pois, somente a partir do momento em que os sujeitos passem a se perceber como parte integrante do espaço em que atuam, e que sua prática está intimamente ligada ao seu fazer, é que se torna possivel a aprendizagem.

Sendo assim, para o campo, não cabe mais o formato pronto e os manuais vindos da cidade, somente para a execução, pois se faz ne- cessário interagir com o universo dos alunos, sejam eles crianças, jovens ou adultos, de maneira significativa.

Os desafios apresentados para a Educação e a construção de um ideal contemporâneo necessitam, mediante o que aqui se discute, provocar, conforme Morin (1999), a reforma do pensamento, contextualizando e globalizando os saberes na lógica de um novo espírito científico, e encarando, dessa maneira, as contradições contemporâneas e, assim, proporcionando um diálogo permanente entre a concepção de ciência e a contemporaneidade, pela via do saber.

O diálogo aqui evidenciado é algo que surge a todo instante, na fala da professora, e nos provoca a construir reflexões constantes sobre o quanto a sua prática é formativa e se traduz, em sua vida, pela necessidade emergente de manter um diálogo permanente com as mudanças que se dão no âmbito das relações entre o professor e o aluno, de maneira particular, no Ensino Médio. A dimensão de como os diálogos se estabelecem, considerando o vivido e experienciado pelos sujeitos, denota uma possibilidade subjetiva que alavanca outras condições para o encontro e o desencontro nas ações da docência:

[...] você olha assim e observa a diferença que é o jovem, o desejo que é o jovem também da localidade rural, mas diferente de outra localidade e também a visão errônea que muitos de nós da cidade temos desses jovens, a gente muda, acha que muitos deles são totalmente longe da realidade, não são antenados, não sabem frequentar as redes sociais, não têm contato com a internet de modo geral, que falar pra eles computador é uma coisa do outro mundo, não é! Chegar pra eles e falar a respeito do que é moda pra eles, não é, eu chegava aqui, eu sou muito, eu sou curiosa e queria saber como eles observam a gente, aí eu sou muito de observar, e aí eu chegava assim, gente, eu tenho que me atualizar. Por que professora? Eu estou muito, muito desatualizada e outra coisa, eu sou muito 
antiquada, vocês são antenados demais. (FLOR DE MANDACARU, ENTREVISTA NARRATIVA, 2015)

A visão de uma geração para outra é demarcada principalmente quando os elementos que hoje são vividos pelos sujeitos constroem estranhamento e a pertinência cotidiana desse olhar permite ao educador avançar na construção do conhecimento coletivo e da aproximação entre as pessoas. Assim, o diálogo intergeracional precisa pautar-se pela não linearidade, para além de um tempo externo e mecanicista, pois há uma busca por construir novos olhares que possibilitem repensar o fluxo temporal da história (WELLER, 2005), no caso, entre o professor e o aluno jovem do Ensino Médio, uma vez que esse é o objeto de discussão que aqui se desenvolve.

Para romper, então, com a barreira do distanciamento entre sua forma de pensar e fazer, no processo formativo, a professora Flor de Mandacaru adota técnicas diferenciadas e aulas "maleáveis", como relata em sua narrativa. Além destas questões, ela se propõe a construir uma relação de proximidade com os alunos, em sua diversidade e diferença etária, ao contrário de impor o seu pensamento e sua perspectiva de objetivar o mundo, mas propondo aos estudantes pensar e construir suas próprias dimensões teóricas, validando, na perspectiva do encontro geracional, a valoração dos elementos subjetivos de cada sujeito.

[...] o conteúdo de hoje é esse, mas como é que eu vou fazer o meu aluno aqui da área rural, com a vivência que ele tem, entender que isso é importante para a vida dele e ele se sentir motivado pra entender esse assunto, para estudar esse assunto, sem que tenha nada em referência à vivência dele, então, a gente precisa ter esse olhar, ter essa visão, de olhar de onde é que eu tenho meu aluno. (FLOR DE MANDACARU, ENTREVISTA NARRATIVA, 2015)

Ao considerar que é preciso conhecer bem o seu aluno, para assim garantir que ele consi- ga avançar no aprendizado, uma vez que o conteúdo irá dialogar diretamente com a vivência dele, a professora adota uma das vertentes do fazer na docência que toma outra característica ou viés do processo formativo. Nesse sentido, vai de encontro à lógica da aprendizagem significativa e contextualizada, já mencionadas ao longo do texto, porém, com maior destaque para produzir no sujeito não apenas o conhecimento sistematizado e com vistas à inserção no mercado de trabalho. 0 desafio de ressignificação da prática docente e do processo formativo está exatamente na garantia de que os sujeitos envolvidos possam, por eles mesmos, pensar e construir suas dimensões teóricas, romper com os seus paradigmas e fazer surgirem novos. A ruptura não se dá de maneira simples e imediata, é um processo longo, que caminha para o encontro de si.

Tais aspectos são muito marcados na narrativa da docente e respaldados pelo que vem se construído nas pesquisas em Educação, onde os resultados dos estudos apontam para a pertinência de que a autobiografia e a reflexão de si proporcionam ao sujeito a reinvenção de sua prática e de sua constituição, enquanto um sujeito no mundo e para o mundo. Quando a narradora diz "gosto de observar as diferenças das pessoas" e atrela essa observação ao seu processo de aprendizagem pessoal, permitenos validar que a subjetividade presente em cada sujeito é um campo vasto para se construir ou ressignificar os processos formativos na docência, sejam eles, para os professores ou dos professores para com os seus alunos, de modo particular, os jovens estudantes, uma vez que está propício ao encontro com seus movimentos experienciais.

\section{Últimos fios narrativos: aspectos conclusivos para o momento}

Durante toda a narrativa, a professora constrói um diálogo permanente com o seu processo 
formativo, entrecruzado as suas vivências no labor cotidiano da sala de aula, intercalando as relações de familiares, sociais e culturais, em que ela está inserida. Demonstra com muita clareza a pertinência e a influência do contexto para o desenvolvimento de sua prática. Alguns marcadores temporais são usados para tecer a narrativa, considerados, assim, como os fios que conduzem o tecido de sua fala. Ao partir das relações familiares e de seu vínculo com o espaço rural, começa a demarcar uma construção subjetiva própria que a lança para a busca contínua do entendimento de si a partir das relações com os outros.

Em um processo de alteridade, constrói uma prática profissional em que não se deixa abater ou intimidar pelas dificuldades lançadas ao longo de sua constituição profissional. Em todas as suas experiências, demarca muito claramente a importância da atuação no Ensino Médio e fortalece dessa maneira a emergência da necessidade de se voltar o olhar para o ensino de jovens, uma vez que se trata da finalização de um ciclo inicial da formação escolarizada, nas sociedades contemporâneas. Ao narrar o momento em que atua no Ensino Médio, demonstra sua satisfação profissional, após trabalhar em todos os níveis e modalidades de ensino, que a experiência do trabalho no campo é marcante. Demonstra entusiasmo, e o que isso significa para a profissão e para a vida da docente: “[...] e aí quando chega aqui eu ensinando em fundamental II e aí chega essa oportunidade de ensinar no médio e a minha felicidade destes anos todos até 2013" (FLOR DE MANDACARU, ENTREVISTA NARRATIVA, 2015).

Provocar um diálogo proficuo entre docente e jovem é apresentado aqui como uma das maiores intervenções e necessidade para que o ensino médio surta de fato efeito na formação destes sujeitos, sendo, ainda, essencial para o desenvolvimento da profissão docen- te e a formação destes sujeitos. Na junção de experiências distintas de uma mesma geração já é difícil estabelecer um diálogo que seja mediado com facilidade, mas esse desafio é potencializado quando os tempos e vivências que se cruzam são muito diferentes.

Possibilitar ou ampliar o diálogo intergeracional é para esse trabalho o elemento que elucida a condição formativa dos sujeitos envolvidos no processo. Inferir as possibilidades de ampliação do conhecimento, pela via de estreitar esses laços e aproximá-los do contexto em que se vive, e ampliá-lo para a constituição curricular e pedagógica, é a mola mestra para a mudança e a quebra de paradigmas, no âmbito educacional. A ruptura com os vínculos e amarras que não permitem o encontro com as subjetividades torna-se a possibilidade de crescimento e avanço, no âmbito da educação ofertada para o Ensino Médio no contexto rural.

\section{Referências}

ARROYO, Miguel. Repensar o Ensino Médio: Por quê? In: DAYRELL, Juarez; CARRANO, Paulo; MAIA, Carla Linhares. (Orgs.). Juventude e ensino médio: sujeitos e currículos em diálogo. Belo Horizonte: Editora da UFMG, 2014. p. 54-74.

BERTAUX, Daniel. Narrativa de vida: a pesquisa e seus métodos. Tradução de Zuleide Alves Cardoso Cavalcante e Denise Maria Gurgel Lavallée. Natal: EDUFRN; São Paulo: Paulus, 2010.

BRASIL. Conselho Nacional de Educação. Parecer CNE/CEB n. 5/2011. Diretrizes Curriculares Nacionais para o Ensino Médio. Diário Oficial da União, Poder Executivo, Brasília, DF, 24 jan. 2011. Seção 1, p. 10.

BRASIL. Nova delimitação do semiárido brasileiro. Secretaria de Desenvolvimento Regional. Ministério da Integração Nacional. Brasília, DF, 2008.

CARNEIRO, Maria José. Apresentação. In: MOREIRA, R. (Org.). Identidades sociais: ruralidades no Brasil contemporâneo. Rio de Janeiro: DP\&A, 2005. p. 07-13.

CARNEIRO, Maria José. Multifunciolnalidade da agri- 
cultura e ruralidade: uma abordagem comparativa. In: MOREIRA, R.; COSTA, L. F. (Orgs.). Mundo rural e cultura. Rio de Janeiro: MAUAD, 2002. p. 223-240.

DELORY-MOMBERGER, Christine. Biografia e educação: figuras do indivíduo-projeto. Tradução de Maria da Conceição Passeggi, João Gomes da Silva Neto e Luis Passeggi. Natal: EDUFRN; São Paulo: Paulus, 2008.

GADAMER, Hans-Georg. Verdade e método. Tradução de Flávio Paulo Meurer. Petrópolis, RJ: Vozes, 1997.

GOTTMANN, Jean. A evolução do conceito de território. Boletim Campineiro de Geografia, Campinas, SP, v. 2, n. 3, p. 523-545, 2012.

FREIRE, Paulo. Educação e mudança. 4. ed. São Paulo: Paz e Terra, 1981.

JOSSO, Marie-Christine. A experiência de vida e formação. Tradução de José Cláudio e Júlia Ferreira; 2. ed. rev. e ampl. Natal: EDUFRN; São Paulo: Paulus, 2010.

JOVCHELOVITCH, Sandra; BAUER, Martin W. Entrevista narrativa. In: BAUER, Martin W.; GASKELL, George. Pesquisa qualitativa com texto, imagem e som: um manual prático. Tradução de Pedrinho Guareschi. 6. ed. Petrópolis, RJ: Vozes, 2007. p. 90-113.

MARTINS, Josemar da Silva. Contextualizando contexto. Caderno Multidisciplinar: Educação e contexto no semiárido brasileiro. Múltiplos espaços para o exercício da contextualização. Juazeiro, BA: Selo Editorial RESAB, 2009.

MOREIRA, Roberto José. Ruralidades e globalizações: ensaiando uma interpretação. In: MOREIRA, Roberto José et al. (Orgs.). Identidades sociais: ruralidades no Brasil contemporâneo. Rio de Janeiro: DP\&A, 2005. p. 15-40.

MOTA, D. M. da.; SCHMITZ, H. Pertinência da categoria rural para análise do social. Revista Ciências Agrotécnicas, Lavras, v. 26, n. 2, p. 392-399. mar./abr. 2002.

MORIN, Edgar. A cabeça bem-feita: repensar a reforma, reformar o pensamento. Tradução de Ana Paula Viveiros. Lisboa: Instituto Piaget, 1990.

OLIVEIRA, Adelson Dias de. Jovens no semiárido baiano: experiências de vida e formação no campo. 2014. 138 f. Dissertação (Mestrado em Educação e Contemporaneidade) - Programa de Pós-Graduação em Educação e Contemporaneidade, Universidade do Estado da Bahia, Salvador, 2014.

PIMENTEL, Álamo. 0 encontro e a troca: ensaios antropológicos do aprende e genealogias do conviver. Salvador: EDUFBA, 2013.

RAMOS, Renata Fornelos d'Azevedo. Juventude e trabalho: um paradoxo contemporâneo. In: NASCIMENTO, Antônio Dias; CHAVES, Rosana Mara Rodrigues; SODRÉ, Maria Dorath Bento. (Orgs.). Educação do campo e contemporaneidade. Salvador: EDUFBA, 2013. p. 273-289.

REIS, Edmerson dos Santos; SANTOS JÚNIOR, Paulo Anunciação dos. Da práxis à fundamentação: elementos para pensar a relação Educação do Campo e o desenvolvimento local. In: NASCIMENTO, Antônio Dias; CHAVES, Rosana Mara Rodrigues; SODRÉ, Maria Dorath Bento. (Orgs.). Educação do campo e contemporaneidade. Salvador: EDUFBA, 2013. p. 129-145.

RICOEUR, P. Teoria da interpretação. Tradução de Artur Morão. Lisboa: Edições 70, 1996.

RIOS, Jane Adriana Vasconcelos Pacheco; VICENTINI, Paula Perin. Docência e profissionalização: experiências de professores leigos na roça. In: VICENTINI, Paula Perin; SOUZA, Elizeu Clementino de.; PASSEGGI, Maria da Conceição. (Orgs.). Pesquisa (auto)biográfica: questões de ensino e formação. Curitiba: CRV, 2013. p. 111-130.

SOUZA, Elizeu Clementino de. A arte de contar e trocar experiências: reflexões teórico-metodológicas sobre história de vida em formação. Revista Educação em Questão, Natal, v. 25, n. 11, p. 22-39, jan./ abr. 2006.

SOUZA, Elizeu Clementino de. Histórias de vida, escritas de si e abordagem experiencial. In: SOUZA, E. C.; MIGNOT, A. C. V. (Orgs.). Histórias de vida e formação de professores. Rio de Janeiro: Quartet; Faperj, 2008. p. 89-98.

SOUZA, Elizeu Clementino de et al. Sujeitos, instituições e práticas pedagógicas: tecendo as múltiplas redes da educação rural na Bahia. Revista da FAEE- 
BA - Educação e Contemporaneidade, Salvador, v. 20, n. 36, p. 151-164, jul./dez. 2011.

SOUZA, Elizeu Clementino de. Diálogos cruzados sobre pesquisa (auto)biográfica: análise compreensiva -interpretativa e política de sentido. Revista Educação, Santa Maria, v. 39, n. 1, p. 39-50, jan./abr. 2014.

VEIGA, José Eli da. Cidades imaginárias: o Brasil é menos urbano do que se calcula. Campinas, SP: Autores Associados, 2002.

WANDERLEY, Maria de Nazareth Baudel. A emergência de uma nova ruralidade nas sociedades moder- nas avançadas: o "rural" como espaço singular e ator coletivo. Estudos Agricultura e Sociedade, Rio de Janeiro, n. 15, p. 87-145, out. 2000.

WELLER, Wivian. A atualidade do conceito de gerações de Karl Mannheim: perspectivas para a análise das relações entre educação e trabalho. In: ENCONTRO ANUAL DA ANPOCS, 29., Caxambu. Anais... Caxambu: ANPOCS, 2005. p. 01-16.

Adelson Dias de Oliveira é Doutorando em Educação e Contemporaneidade pelo Programa de Pós-Graduação em Educação e Contemporaneidade (PPGEduC) da Universidade do Estado da Bahia (UNEB). Professor da Universidade Vale do São Francisco - Campus de Juazeiro/BA. Membro do grupo de pesquisa Docência, Narrativas e Diversidade - DIVERSO/ UNEB. Vice-líder do Núcleo de Pesquisas em Juventudes - NUJUVES/UNIVASF. e-mail: adelsonjovem@gmail.com

Rua São Francisco, 318, Bloco 15, apto 202, Condomínio Mais Viver, Juazeiro/BA. CEP: 48904 - 723. Tel: (87)9 99981-7433.

Fabrício Oliveira da Silva é Doutor em Educação pelo Programa de Pós-Graduação em Educação e Contemporaneidade (PPGEduC) da Universidade do Estado da Bahia (UNEB). Professor da Universidade do Estado da Bahia - UNEB. Membro do grupo de pesquisa Docência, Narrativas e Diversidade - DIVERSO. e-mail:- faolis@ig.com.br

Rua Dr. Macário Cerqueira, 879 - apt. 602 - Torre Hibisco, Condomínio Vila das Flores. Feira de Santana/BA. CEP: 44005-000 - Tels: (75) 9 8817-9194 e 9 9154-9734. 